\title{
Revista Motricidade: Uma questão de compromisso com a ciência e a cultura lusófona
}

\author{
Journal Motricidade: A matter of commitment to the lusophone science \\ and culture
}

\section{Eduardo Leite ${ }^{1 *}$}

Os protótipos das primeiras revistas científicas surgiram por iniciativa de académicos franceses e ingleses em 1665. Na época, estes académicos usaram versões impressas dos seus trabalhos para distribuírem e divulgarem os seus pensamentos e revelações científicas para fora dos seus círculos profissionais.

Desde então, as revistas científicas têm vindo a proliferar e a desempenhar uma função relevante na comunicação e divulgação do conhecimento, tanto em papel, como, mais recentemente através da internet, em formato digital. Ao divulgarem a ciência, as revistas veiculam também uma parte da cultura de um país e de um povo.

É neste contexto que a Revista Motricidade intervém. A sua missão é disseminar o conhecimento científico de caráter teórico e empírico nas áreas científicas do desporto, psicologia e desenvolvimento humano, e saúde. A sua responsabilidade social é veicular e defender uma parte da cultura lusófona no mundo.

No cumprimento da sua missão ao longo destes dez anos de atividade, a Motricidade conta já com dezenas de edições e várias centenas de artigos publicados. A Motricidade é a publicação líder de mercado em Portugal. No Brasil, a Motricidade está entre as publicações de melhor qualidade, aferida pela quantidade e qualidade das indexações, o que se tem traduzido num aumento da procura de autores brasileiros para divulgarem os seus trabalhos na Motricidade.
Assim, não podia deixar passar esta oportunidade em que estamos a celebrar o décimo aniversário da Motricidade, para apresentar os meus parabéns a toda a equipa pelo trabalho realizado.

Relativamente à atual edição da Motricidade, esta apresenta uma vez mais, um conjunto variado de textos e temas, sendo de destacar que mais de cinquenta por cento dos artigos fazem uma associação direta do desporto à saúde. Os restantes artigos revelam uma preocupação com a evolução do treino desportivo em modalidades, como a natação, o ténis e o rugby.

A leitura desta edição da Motricidade renova o contato com princípios de conhecimento universal, tais como: "A prática regular de desporto é uma fonte de saúde e bem estar" ou "a inovação na investigação melhora o rendimento desportivo". A edição apresenta, também, questões metodológicas detalhadas de treino, onde os leitores podem consolidar o conhecimento dessas máximas desportivas, sintetizadas desde há muito tempo atrás pelo poeta satírico romano Juvenal, através do aforismo "mens sana in corpore sano". Passar da leitura à prática, depende apenas de nós e exige esforços mínimos. Já os benefícios de crescer e viver numa mente em harmonia com o corpo são muito compensadores.

Votos de boa leitura

\footnotetext{
${ }^{1}$ Diretor da Revista Motricidade; Fundação Técnica e Científica do Desporto, Portugal

* Autor correspondente: Fundação Técnica e Científica do Desporto, Travessa Prof ${ }^{a}$ Márcia Caldeira, 8, 4410-147 São Félix da Marinha - Vila Nova de Gaia, Portugal; E-mail: eduardoleit@gmail.com
} 